\title{
Identification of early diagnostic antigens from major excretory-secretory proteins of Trichinella spiralis muscle larvae using immunoproteomics
}

\author{
Li Wang, Jing Cui, Dan Dan Hu, Ruo Dan Liu and Zhong Quan Wang ${ }^{*}$
}

\begin{abstract}
Background: The excretory-secretory (ES) proteins of Trichinella spiralis muscle larvae (ML) come mainly from the excretory granules of the stichosome and the cuticles (membrane proteins), are directly exposed to the host's immune system, and are the main target antigens, which induce the immune responses. Although the ES proteins are the most commonly used diagnostic antigens for trichinellosis, their main disadvantage are the false negative results during the early stage of infection. The aim of this study was to identify early specific diagnostic antigens from the main components of T. spiralis muscle larval ES proteins.
\end{abstract}

Methods: Two-dimensional electrophoresis (2-DE) combined with Western blot were used to screen the early diagnostic antigens from the main components of T. spiralis muscle larval ES proteins. The protein spots recognized by the sera from BALB/c mice infected with T. spiralis at 18 days post-infection (dpi) were identified by MALDI-TOF/ TOF-MS and putatively annotated using GO terms obtained from the InterPro databases.

Results: The ES proteins were analyzed by 2-DE, and more than 33 protein spots were detected with molecular weight varying from 40 to $60 \mathrm{kDa}$ and isoelectric point (pl) from 4 to 7 . When probed with the sera from infected mice at $18 \mathrm{dpi}, 21$ protein spots were recognized and then identified, and they were characterized to correlate with five different proteins of T. spiralis, including two serine proteases, one deoxyribonuclease (DNase) II, and two kinds of trypsin. The five proteins were functionally categorized into molecular function and biological process according to GO hierarchy.

Conclusions: 2-DE and Western blot combined with MALDI-TOF/TOF-MS were used to screen the diagnostic antigens from the main components of T. spiralis muscle larval ES proteins. The five proteins of T. spiralis identified (two serine proteases, DNase II and two kinds of trypsin) might be the early specific diagnostic antigens of trichinellosis.

Keywords: Trichinella spiralis, Muscle larvae, Excretory-secretory proteins, Early diagnostic antigens, Mass spectrometry

\section{Background}

Trichinellosis is a widespread parasitic zoonosis caused by the ingestion of raw or inadequately cooked meat containing the infective larvae of the nematode genus Trichinella [1]. In the past few decades, many outbreaks of human trichinellosis have been reported in different areas of the world [2-4]. From 2004 to 2009, 15 outbreaks of human trichinellosis, consisting of 1387 cases and 4 deaths, were

\footnotetext{
*Correspondence: cuij@zzu.edu.cn; wangzq@zzu.edu.cn

Department of Parasitology, Medical College, Zhengzhou University, 40 Daxue Road, Zhengzhou 450052, P. R. China
}

reported in China [5]. So, trichinellosis is not only a public health hazard that affects patients but also represents an economic problem in porcine animal production and food safety [6].

The clinical diagnosis of trichinellosis is rather difficult because its clinical manifestations are nonspecific $[7,8]$. At present, muscle biopsy and serologic tests are used for diagnosing human trichinellosis $[9,10]$. The sensitivity of muscle biopsy depends on the amount of muscle sample tested and the degree of infection. Muscle biopsy is not sensitive to the light infections and the early stage of 
infection. Serologic tests [e.g., enzyme-linked immunosorbent assay (ELISA) using muscle larval excretory-secretory (ES) antigen or the synthetic antigen 3,6-dideoxy-D-arabinohexose (tyvelose)] for detecting the specific anti-Trichinella antibody IgG are not positive in pigs and mice infected experimentally until 3-4 weeks after infection [11-13]. The detection of IgG antibodies to Trichinella by ELISA using ES antigens of $T$. spiralis muscle larvae (ML) is commonly used for diagnosis of trichinellosis [9]. However, the main disadvantage of detection of IgG antibodies is the occurrence of a high rate of false negative results during the early stage of infection. Several studies have shown that the maximum detection rate of $100 \%$ of IgG antibodies was not reached until at least 1-3 months after human infection with the parasite [11,14]. The T. spiralis ML ES proteins were analyzed by SDS-PAGE or 2-DE gel analysis $[15,16]$. In the previous study, we attempted to identify early diagnostic antigens in T. spiralis ES proteins with molecular weights of 30-40 kDa [17]. However, The 40$60 \mathrm{kDa}$ ES proteins of $T$. spiralis, which are the major antigenic proteins, have received more attention than other ES proteins because these proteins are candidates of immunodiagnostic antigens for trichinellosis and are present in much greater amounts in the ES products [18]. In this study, an attempt is made to screen early specific antigens from the most abundant proteins of T. spiralis ML ES proteins, which might be valuable for the early diagnosis of trichinellosis.

Immunoproteomics could be defined as the combination of any proteomic technology with an immunological data presentation [19]. Its development is vital in an age where it is increasingly becoming urgent to identify disease biomarkers and pathogenic target antigens for diagnosis and the development of new drugs and vaccines. Among the current proteomic techniques available [20], 2-DE has often been chosen as the research tool in immunoproteomic applications in combination with Western-blot [19]. In the present study, we identified the early specific diagnostic antigens from the main components of T. spiralis ML ES proteins using immunoproteomic methods.

\section{Methods}

\section{Parasite and experimental animals}

T. spiralis isolate (ISS534) used in this study was obtained from a domestic pig in Nanyang city of Henan Province, China. The isolate was maintained by serial passages in Kunming mice in our laboratory. Muscle larvae were recovered from the mice infected with $T$. spiralis at $42 \mathrm{dpi}$ by artificial digestion as described previously [21,22]. Specific pathogen free (SPF) female BALB/c mice aged 6 weeks were purchased from the Experimental Animal Center of Henan province (Zhengzhou, China). The permission (No. SCXK 2010-0002) was given by the Science and Technology Department of Henan Province.

\section{Collection of infection sera and determination of anti-Trichinella antibodies}

BALB/c mice were orally infected with 300 larvae/mouse and the serum samples from the infected mice were collected as described previously [23]. About $100 \mu \mathrm{l}$ of tail vein blood was daily collected from each mouse before infection and during 14-42 dpi, respectively. The anti-Trichinella IgG antibodies of infected mice during 14-42 dpi were determined by the ELISA and Western blot methods using T. spiralis ML ES proteins as antigens. The specific antibodies were firstly detected at $18 \mathrm{dpi}$ by the abovementioned two methods and persisted to $42 \mathrm{dpi}$ (data not shown). The early (18 dpi) and late (42 dpi) infection sera were used to detect the fractions of ES proteins in the following Western blot analysis.

\section{Preparation of ES proteins}

Preparation of ES proteins was performed as previously described $[24,25]$. Briefly, after being washed thoroughly in sterile saline and serum-free RPMI-1640 medium supplemented with $100 \mathrm{U}$ penicillin/ml and $100 \mu \mathrm{g}$ streptomycin $/ \mathrm{ml}$, the larvae were incubated in the same medium at 5000 worms $/ \mathrm{ml}$ for $18 \mathrm{~h}$ at $37^{\circ} \mathrm{C}$ in $5 \% \mathrm{CO}_{2}$. After incubation, the media containing the ES proteins were poured into $50-\mathrm{ml}$ conical tubes and the larvae were allowed to settle for $20 \mathrm{~min}$. The supernatant containing the ES products was filtered through a $0.2 \mu \mathrm{m}$ membrane. The ES products were dialyzed and then lyophilized by a vacuum concentration and freeze-drying (Heto Mxi-Dry-Lyo, Denmark). The protein concentration was determined by the Bradford assay [26].

\section{2-DE and Western blot}

The ES proteins were precipitated using trichloroacetic acid (TCA) and acetone using a previously described method with some modifications [27]. The electrophoresis was performed as described previously $[17,28]$. Briefly, 300 or $200 \mu \mathrm{g}$ of ES proteins were loaded onto 11-cm pH 4-7 immobilized pH gradient (IPG) strips (Bio-Rad, USA) and separated by isoelectric focusing (IEF). IEF was performed using a Protean IEF Cell at $20^{\circ} \mathrm{C}$ as follows: S1: $50 \mathrm{~V}, 12 \mathrm{~h}$; S2:250 V, $30 \mathrm{~min}$; S3: $1000 \mathrm{~V}, 30 \mathrm{~min}$; S4: $8000 \mathrm{~V}, 4 \mathrm{~h}$; and S5: $8000 \mathrm{~V}, 40000 \mathrm{Vh}$ (using a limit of $50 \mu \mathrm{A} /$ strip). SDS-PAGE was performed with $10 \%$ gels using a Mini Protean cell (Bio-Rad, USA). Three replicates were run for the sample. After 2D gel electrophoresis, proteins were either stained with Coomassie blue R-250 for proteomic analysis or used for immunoblotting as previously described [29]. Both the 2-DE and immunoblotting tests were repeated three times, with no variation in results observed. Images of immunoblots were captured using ImageScanner (GE healthcare, USA) and aligned with equivalent protein stained 2-DE gels using Image Master 2D Platinum 6.0 (GE healthcare, USA). 


\section{Protein identification and database searches}

2-DE gel excision and tryptic digestion of 2-DE gel electrophoresis protein spots recognized by early infection sera were prepared for MALDI-TOF/TOF-MS analysis according to standard protocols [30]. The resulting peptides were analyzed by MALDI-TOF/TOF-MS. The procedure was performed as described previously [31]. Combined peptide mass fingerprinting (PMF) and MS/MS queries were performed by using the MASCOT search engine 2.2 (Matrix Science, UK) and submitted to MASCOT Sequence Query server (http://www.matrixscience.com) for identification against nonredundant NCBI database (http://www.ncbi. nlm.nih.gov/BLAST). The criteria for successfully identified proteins were as follows: ion score confidence index (CI) for peptide mass fingerprint and MS/MS data was $\geq 95 \%$.

\section{InterPro annotation and gene ontology (GO) categories}

Functional characterization of Trichinella protein sequences was based on Gene Ontology (GO) Annotation. InterProscan software (http://www.ebi.ac.uk/Tools/ $\mathrm{pfa} / \mathrm{iprscan} /$ ) was used to perform protein sequence searches against InterPro member databases to identify signatures [32]. The resultant proteins were functionally categorized using the Web Gene Ontology Annotation Plot [WEGO, (http://wego.genomics.org.cn/cgi-bin/wego/ index.pl)] [33]. The groups of datasets were simultaneously subjected to online analysis that was convenient to compare them in one graph.

\section{Ethics statement}

All animals were treated in strict accordance to the National Guidelines for Experimental Animal Welfare (MOST of People's Republic of China, 2006). The protocols of the animal experiments reported herein were approved by The Life Science Ethics Committee of Zhengzhou University.

\section{Results}

\section{2-DE analysis of $T$. spiralis ES proteins}

With the purpose of improving the resolution of the spots, IEF was performed in $\mathrm{pH}$ 4-7 narrow range strips in this study. Firstly, the second dimension (SDS-PAGE) was performed using $12 \%$ polyacrylamide gels. After separation, the 2-DE gel was stained with Coomasie blue R-250, and the main components (43, 45, and $53 \mathrm{kDa}$ proteins) of ES proteins were aggregated, which are present in much greater amounts. For better separation of the most abundant proteins, the load amount of ES protein was reduced from 300 to $200 \mu \mathrm{g}$ and SDS-PAGE was performed using $10 \%$ polyacrylamide gels, where the majority of the main components of ES proteins are present but some proteins with low molecular weight disappeared. After IEF in pH 4-7 linear IPG strips and separation by 10\% SDSPAGE with $200 \mu \mathrm{g}$ of ES proteins, more than 33 spots were detected, with molecular weight from 40 to $60 \mathrm{kDa}$ (Figure 1A). The 2-DE was repeated three times, and the patterns were highly reproducible.

\section{Western blot analysis of $T$. spiralis ES proteins following 2-DE}

As shown in Figure 1B, there were more than 25 spots displaying reactivity with the infection sera at $18 \mathrm{dpi}$. Once photographed, the immunoblot and their homologous Coomassie blue-stained gel were aligned and then matched by Image Master 2D Platinum 6.0 software and artificial recognition. A total of 21 immunoreactive protein spots could be confidently matched to the corresponding protein spot in Coomassie blue-stained gels. These matched spots named spot 1 to 21 were selected to be further analyzed by MS. In comparison, when the immunoblot was performed with sera at $42 \mathrm{dpi}$, there were the additional 5 positive spots (Figure 1C) more than the above-mentioned 25 spots, indicating that the 25 positive spots were recognized by both infection sera at $18 \mathrm{dpi}$ and $42 \mathrm{dpi}$, but the stronger reactions were observed with sera at $42 \mathrm{dpi}$, and the additional 5 positive spots were recognized only by infection sera at $42 \mathrm{dpi}$. But, the sera collected from normal mice before infection did not show detectable immunoreactivity with any of the protein spots (Figure 1D).

\section{Identification of immunoreactive proteins by MALDI-TOF/TOF-MS}

Out of all 21 matched protein spots recognized by infection sera at $18 \mathrm{dpi}, 17$ spots were successfully identified. Of these, 16 spots were characterized to correlate with five different proteins of Trichinella, including two serine proteases with different $\mathrm{pI}$ and molecular weight values, one deoxyribonuclease (DNase) II, and two kinds of trypsin, while the other spot was identified as alpha S1 casein of Bos Taurus. The proteins of other 3 spots were identified as protein of other organism species and not matched with that of Trichinella in the NCBI database. Although another protein spot was matched with Trichinella protein, the MOWSE score was only 54, which was unsuccessfully identified. The results of protein identification are shown in Table 1.

\section{Functional categorization of immunoreactive proteins by gene ontology}

To further understand the functions of the proteins identified in this study, the identified 5 protein sequences were putatively annotated using GO terms obtained from the InterPro databases. In addition, the 5 proteins were functionally categorized into molecular function and biological process according to GO hierarchy using WEGO. The classification results of the 5 proteins identified in this study were shown in Figure 2. For the molecular function category, five proteins had catalytic and hydrolase activity. 


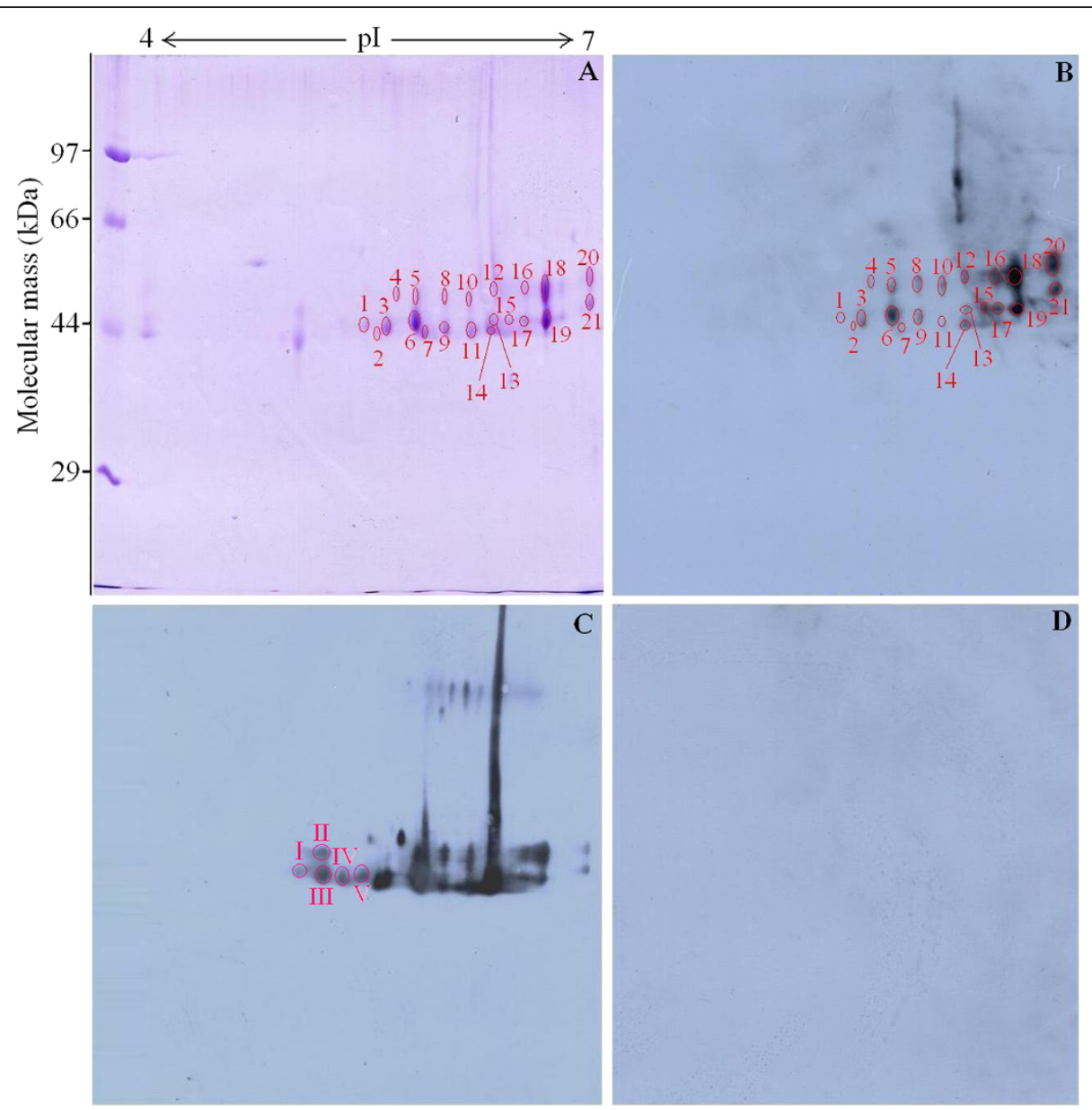

Figure 1 2-DE and Western blot analysis of Trichinella spiralis muscle larval major excretory-secretory (ES) proteins. (A) 2-DE gel of major ES proteins separated in the first dimension in the $\mathrm{pH}$ range 4-7 and then in the second dimension on a 10\% polyacrylamide gel. The gel was stained with Coomassie blue R-250, molecular weight standard is on the left, and pl values are indicated. Protein spots selected for analysis are numbered. (B) 2-DE Western blot of major ES proteins probed by mouse infection sera at 18 days post infection (dpi), and the immunoreactive protein spots were detected by the enhanced chemiluminescent (ECL) kit. (C) 2-DE Western blot of major ES proteins probed by mouse infection sera at $42 \mathrm{dpi}$, I-V was the additional 5 positive spots recognized only by infection sera at $42 \mathrm{dpi}$. D) Western blot map probed by sera from normal mice before infection.

In the biological process category, all of the 5 proteins were also associated with metabolic process.

\section{Discussion}

Parasites are designed by evolution to invade and survive in hosts; they release a variety of molecules that help them to penetrate the defensive barriers and avoid the immune attack of the host [34]. Modulation of the immune response by helminthes involves the ES proteins released by these parasites, including proteases, protease inhibitors, allergen homologues, glycolytic enzymes, lipids and glycans [35,36]. The ES antigens of Trichinella spp. can induce a strong immune response involving the generation of specific antibodies and may be very important for serodiagnosis as they are easily targeted by the host's immune system [37].
In our previous study, after IEF in $\mathrm{pH} 3-10$ nonlinear IPG strips and separation by $12 \%$ SDS-PAGE, the 2-DE gel was stained with Coomasie blue R-250, and most of the protein spots were located between $\mathrm{pH} 4$ and 7 [17]. With the purpose of improving the resolution of the spots, IEF was performed in $\mathrm{pH}$ 4-7 narrow range strips in this study. Previous studies demonstrated that all true positive sera (i.e., sera from persons with confirmed trichinellosis as well as sera from naturally and experimentally infected pigs), reacted with a three-band pattern ranging in size from 48-72 $\mathrm{kDa}$ using ES antigens of T. spiralis ML [38]. The 40-60 kDa ES proteins of $T$. spiralis, which are the major antigenic proteins, have received more attention than other ES proteins because these proteins are candidates of immunodiagnostic antigens for trichinellosis and are present in much greater amounts in the ES products [18]. Hence, in this study, we screened the early specific 
Table 1 Identification of Trichinella spiralis muscle larval major ES proteins recognized by mouse infection sera at 18 dpi using MALDI-TOF/TOF-MS

\begin{tabular}{|c|c|c|c|c|c|c|c|c|}
\hline Spot no. & Protein name & Species & Accession no. & $\begin{array}{c}\text { Theoretical } \\
{\mathrm{Mr} / \mathrm{pl}^{\mathrm{a}}}^{\mathrm{a}}\end{array}$ & $\begin{array}{l}\text { MOWSE } \\
\text { score }^{b}\end{array}$ & Coverage (\%) & $\begin{array}{c}\text { No. matched } \\
\text { peptides }\end{array}$ & $E$-value \\
\hline 1 & Serine protease & T. spiralis & gi|168805931 & $35.7 / 5.97$ & 335 & 22 & 8 & $7 e-027$ \\
\hline 2 & Alpha S1 casein & Bos taurus & gi|159793193 & $18.7 / 5.23$ & 208 & 53 & 8 & $3.5 e-014$ \\
\hline 3 & Putative trypsin & T. spiralis & gi|339241891 & $31.3 / 5.25$ & 132 & 21 & 3 & $1.4 \mathrm{e}-006$ \\
\hline 4 & Unknown & Legionella rubrilucens & gi|61814442 & $12.0 / 6.84$ & 43 & 61 & 5 & $1 e+003$ \\
\hline 5 & Putative trypsin & T. spiralis & gi|339241897 & $53.9 / 5.97$ & 308 & 17 & 8 & $3.5 e-024$ \\
\hline 6 & Serine protease & T. spiralis & gi|168805931 & $35.7 / 5.97$ & 608 & 28 & 6 & $3.5 e-054$ \\
\hline 7 & $\begin{array}{l}\text { Deoxyribonuclease } \\
\text { II family protein }\end{array}$ & T. spiralis & gi|339241449 & $38.1 / 5.97 /$ & 440 & 30 & 8 & $2.2 \mathrm{e}-037$ \\
\hline 8 & Serine protease & T. spiralis & gi|13641204 & $48.7 / 6.33$ & 337 & 18 & 8 & $4.4 \mathrm{e}-027$ \\
\hline 9 & Serine protease & T. spiralis & gi|13641204 & $48.7 / 6.33$ & 200 & 11 & 3 & $2.2 \mathrm{e}-013$ \\
\hline 10 & Serine protease & T. spiralis & gi|13641204 & $48.7 / 6.33$ & 405 & 17 & 7 & 7e-034 \\
\hline 11 & Serine protease & T. spiralis & gi|13641204 & $48.7 / 6.33$ & 347 & 15 & 6 & $4.4 \mathrm{e}-028$ \\
\hline 12 & $\begin{array}{l}\text { Deoxyribonuclease } \\
\text { II family protein }\end{array}$ & T. spiralis & gi|339241449 & $38.1 / 5.95$ & 195 & 28 & 7 & 7e-013 \\
\hline 13 & $\begin{array}{l}\text { Deoxyribonuclease } \\
\text { II family protein }\end{array}$ & T. spiralis & gi|339241449 & $38.1 / 5.95$ & 336 & 34 & 10 & $5.5 e-027$ \\
\hline 14 & Hypothetical protein & Afipia felis & gi|414163749 & $35.7 / 10.2$ & 56 & 36 & 9 & 54 \\
\hline 15 & Hypothetical protein & Pantoea ananatis & gi|378767336 & $35.1 / 10.9$ & 49 & 100 & 4 & $2.7 e+002$ \\
\hline 16 & Serine protease & T. spiralis & gi|13641204 & $48.7 / 6.33$ & 336 & 17 & 8 & $5.5 e-027$ \\
\hline 17 & Serine protease & T. spiralis & gi|13641204 & $48.7 / 6.33$ & 54 & 14 & 5 & 94 \\
\hline 18 & Serine protease & T. spiralis & gi|13641204 & $48.7 / 6.33$ & 304 & 11 & 4 & $8.8 e-024$ \\
\hline 19 & Serine protease & T. spiralis & gi|13641204 & $48.7 / 6.33$ & 443 & 22 & 6 & $1.1 \mathrm{e}-037$ \\
\hline 20 & Serine protease & T. spiralis & gi|168805933 & $48.7 / 6.33$ & 353 & 11 & 9 & $1.1 \mathrm{e}-028$ \\
\hline 21 & Serine protease & T. spiralis & gi|168805933 & $48.7 / 6.33$ & 471 & 20 & 9 & $1.8 \mathrm{e}-040$ \\
\hline
\end{tabular}

${ }^{a}$ Theoretical molecular mass $(\mathrm{kDa})$ and isoelectric point $(\mathrm{pl})$.

${ }^{\mathrm{b}} \mathrm{A}$ MOWSE score of $>70$ was used to assign identity to a protein.

antigens from the main components of ES proteins with 40-60 kDa, which might be valuable for the early diagnosis of trichinellosis. Our results showed that the 21 protein spots were recognized by mouse infection sera at $18 \mathrm{dpi}$ and analyzed by MALDI-TOF/TOF-MS. Out of the 21 protein spots, 16 spots were successfully identified and represented only five different proteins of Trichinella, and all of them were identified to protease: two kinds of serine protease [SP-1.2(gi|168805931), SP-1.3(gi|13641204)] and two kinds of trypsin (gi|339241891 and gi|339241897) belong to the trypsin-like serine protease (Tryp_SPc) superfamily, while the DNase II (gi|339241449) belongs to phospholipase D (PLD_SF) superfamily. Indeed, by comparing our data with the previously published data of the ES proteins with $30-40 \mathrm{kDa}$ recognized by early infection sera using the same approach [17], we found that three kinds of proteins (SP-1.2, SP-1.3, and DNase II) identified in both studies were the same proteins. However, the two studies are complementary inasmuch as two kinds of proteins identified in this study were not identified in our previous study. Combined, both studies have identified seven kinds of proteins from the ES products recognized by early infection sera.

Several experiments have shown that proteolytic enzymes are present in the ES products of $T$. spiralis ML $[39,40]$. Several proteases (such as serine and cysteine) have been identified by substrate gel electrophoresis and characterized according to their $\mathrm{pH}$ optima, substrate specificities and inhibitor sensitivities [31,41]. Moreover, protease can serve as an immunodominant antigen, stimulating a protective immune response [42,43]. In this study, all the five different proteins are identified as protease, which may be synthesized as inactive precursor zymogens that are cleaved during limited proteolysis to generate their active forms.

A previous study has also demonstrated that $T$. spiralis may express more than one isoform of the protein and that a common precursor protein could undergo variable post-translational processing [41]. In this study, three different proteins (SP-1.2, SP-1.3, and DNase II) are identified in multiple protein spots. The results suggested that these proteins might have different isoforms of the same 


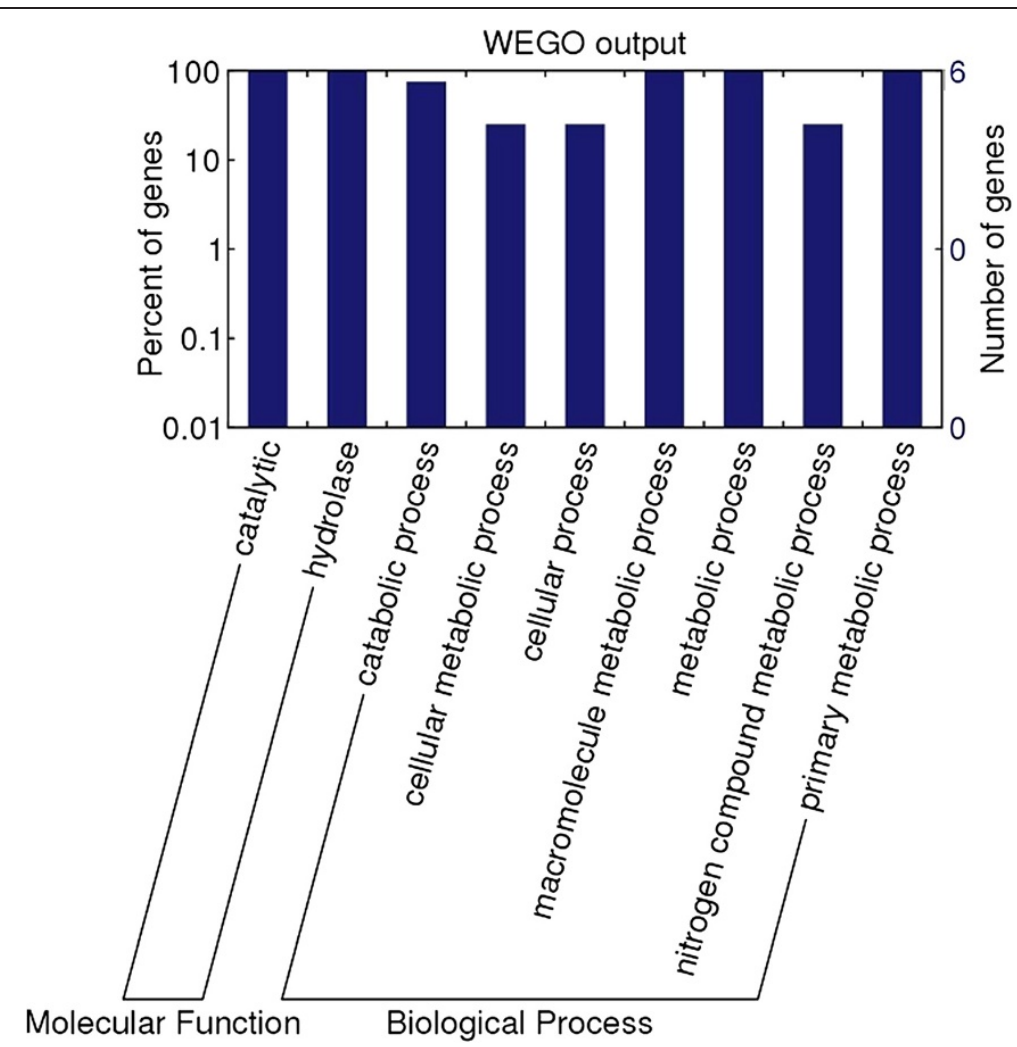

Figure 2 Gene ontology (GO) categories of Trichinella spiralis muscle larval major excretory-secretory (ES) proteins recognized by mouse infection sera at $\mathbf{1 8}$ days post infection (dpi). The identified proteins were classified into molecular function and biological process by WEGO according to their $\mathrm{GO}$ signatures. The number of genes denotes that of proteins with $\mathrm{GO}$ annotations.

protein, or that some of these proteins might be processed by alternative splicing, post-translational modifications and protein processing $[31,44]$. These modifications could be related to phosphorylation or acetylation of the proteins after translation, and they could be vital for the protein's biological functions, such as parasite survival, immune escape and immunopathogenesis. Three spots (7, 12, and 13) were identified as DNase II, which may have DNase II $\alpha$ activity. DNase II $\alpha$ is an acidic endonuclease and was found in lysosomes and nuclei [45]. The secretion of DNase II by T. spiralis may enhance the degradation of released DNA that had not yet been cleared by phagocytes, which may have evolved to affect the availability and down-regulation of host inflammatory processes [46]. Furthermore, this prediction is supported by the evidence that there are a variety of other nucleotide-metabolizing enzymes in $T$. spiralis that were postulated to suppress the proinflammatory effects of these nucleotides [47]. Moreover, 4 protein spots were identified as protein of other organism species and not matched with that of Trichinella in the NCBI database. Spot 2 was identified as alpha S1 casein of Bos taurus, which belongs to the alpha-casein family and plays an important role in the capacity of milk to transport calcium phosphate. Spot 14 was identified as hypothetical protein of Afipia felis, which contains one HTH lysR-type DNAbinding domain. Spot 4 was matched to an unknown protein of Legionella rubrilucens while spot 15 was identified as hypothetical protein of Pantoea ananatis. Besides, twelve spots $(1,6,8,9,10,11,16,17,18,19,20$ and 21) are matched to TspSP-1, but they have the different MW and pI. Multigene protease families have been found in numerous parasites such as Fasciola hepatica [48], Haemonchus contortus [49] and Aspergillus flavus [50]. Each member of the protease families may have a specific role dependent on particular regulation (constitutive or stage-specific), location (intestinal tract or excreted), the presence of a regulatory domain (in $\mathrm{N}$ or $\mathrm{C}$ terminal part) or variations in the amino acid sequence [51]. The above-mentioned five proteins from $T$. spiralis major ES proteins recognized by early infection sera might be the early specific diagnostic antigens for trichinellosis, which needs to be confirmed in further experiments.

\section{Conclusions}

In this study, 2-DE and Western blot combined with MALDI-TOF/TOF-MS was used to screen the diagnostic antigens from the main components of $T$. spiralis muscle larval ES proteins. The main components of $T$. spiralis 
muscle larval ES proteins recognized by early infection sera were analyzed by MALDI-TOF/TOF-MS. The five T. spiralis proteins identified (two serine proteases, DNase II and two kinds of trypsin) might be the early specific diagnostic antigens of trichinellosis. The results suggest that immunoproteomics is a useful approach to identify the early diagnostic antigens.

\section{Competing interests}

The authors declare that they have no competing interests.

\section{Authors' contributions}

ZQW and JC conceived and designed the experiments. LW, JC, DDH, RDL and ZQW performed the experiments. LW, JC and ZQW, analyzed the data and wrote the manuscript. All authors read and approved the final version of the manuscript.

\section{Acknowledgements}

This work was supported by the National Natural Science Foundation of China (No. 81271860, 81141084 and 81371843).

Received: 28 November 2013 Accepted: 17 January 2014

Published: 22 January 2014

\section{References}

1. Murrell KD, Pozio E: Worldwide occurrence and impact of human trichinellosis, 1986-2009. Emerg Infect Dis 2011, 17(12):2194-2202.

2. Gottstein B, Pozio E, Nockler K: Epidemiology, diagnosis, treatment, and control of trichinellosis. Clin Microbiol Rev 2009, 22(1):127-145.

3. Pozio E: World distribution of Trichinella spp. infections in animals and humans. Vet Parasitol 2007, 149(1-2):3-21.

4. Rhee JY, Hong ST, Lee HJ, Seo M, Kim SB: The fifth outbreak of trichinosis in Korea. Korean J Parasitol 2011, 49(4):405-408.

5. Cui J, Wang ZQ, Xu BL: The epidemiology of human trichinellosis in China during 2004-2009. Acta Trop 2011, 118(1):1-5.

6. Cui J, Jiang P, Liu LN, Wang ZQ: Survey of Trichinella infections in domestic pigs from northern and eastern Henan, China. Vet Parasitol 2013, 194(2-4):133-135.

7. Dupouy-Camet J, Kociecka W, Bruschi F, Bolas-Fernandez F, Pozio E: Opinion on the diagnosis and treatment of human trichinellosis. Expert Opin Pharmacother 2002, 3(8):1117-1130.

8. Wang ZQ, Cui J, Wu F, Mao FR, Jin XX: Epidemiological, clinical and serological studies on trichinellosis in Henan Province, China. Acta Trop 1998, 71(3):255-268.

9. Gomez-Morales MA, Ludovisi A, Amati M, Cherchi S, Pezzotti P, Pozio E: Validation of an enzyme-linked immunosorbent assay for diagnosis of human trichinellosis. Clin Vaccine Immunol 2008, 15(11):1723-1729.

10. Yera H, Andiva S, Perret C, Limonne D, Boireau P, Dupouy-Camet J: Development and evaluation of a Western blot kit for diagnosis of human trichinellosis. Clin Diagn Lab Immunol 2003, 10(5):793-796.

11. Gamble HR, Pozio E, Bruschi F, Nockler K, Kapel CM, Gajadhar AA: International Commission on Trichinellosis: recommendations on the use of serological tests for the detection of Trichinella infection in animals and man. Parasite 2004, 11(1):3-13.

12. Kapel CM, Gamble HR: Infectivity, persistence, and antibody response to domestic and sylvatic Trichinella spp. in experimentally infected pigs. Int J Parasitol 2000, 30(2):215-221.

13. Wang J, Cui J, Wang ZQ: Serum IgG levels in the mice experimentally infected with Trichinella spp. Chin J Pathog Biol 2007, 2(4):266-268.

14. Bruschi F, Tassi C, Pozio E: Parasite-specific antibody response in Trichinella sp. 3 human infection: a one year follow-up. Am J Trop Med Hyg 1990, 43(2):186-193.

15. Auxiliadora Dea-Ayuela M, Bolas-Fernandez F: Dynamics of the lgG3 responses following immunisation of BALB/C mice with somatic and excretory/secretory antigens from various Trichinella species. Folia Parasitol (Praha) 2000, 47(3):172-180.

16. Wu Z, Nagano I, Takahashi Y: A panel of antigens of muscle larvae of Trichinella spiralis and T. pseudospiralis as revealed by two-dimensional western blot and immunoelectron microscopy. Parasitology 1999, 118((Pt 6):615-622.

17. Wang L, Wang ZQ, Hu DD, Cui J: Proteomic analysis of Trichinella spiralis muscle larval excretory-secretory proteins recognized by early infection sera. Biomed Res Int 2013, 2013:139745.

18. Nagano I, Wu Z, Takahashi Y: Functional genes and proteins of Trichinella spp. Parasitol Res 2009, 104(2):197-207.

19. Klade CS: Proteomics approaches towards antigen discovery and vaccine development. Curr Opin Mol Ther 2002, 4(3):216-223.

20. Steel LF, Haab BB, Hanash SM: Methods of comparative proteomic profiling for disease diagnostics. I Chromatogr B Analyt Technol Biomed Life Sci 2005, 815(1-2):275-284

21. Gamble HR, Bessonov AS, Cuperlovic K, Gajadhar AA, van Knapen F, Noeckler K, Schenone H, Zhu X: International Commission on Trichinellosis: recommendations on methods for the control of Trichinella in domestic and wild animals intended for human consumption. Vet Parasitol 2000, 93(3-4):393-408

22. Li F, Cui J, Wang ZQ, Jiang P: Sensitivity and optimization of artificial digestion in the inspection of meat for Trichinella spiralis. Foodborne Pathog Dis 2010, 7(8):879-885.

23. Li F, Wang ZQ, Cui J: Early detection by polymerase chain reaction of migratory Trichinella spiralis larvae in blood of experimentally infected mice. Foodborne Pathog Dis 2010, 7(8):887-892.

24. Zhang YL, Wang ZQ, Li LG, Cui J: Molecular characterization of Trichinella spiralis aminopeptidase and its potential as a novel vaccine candidate antigen against trichinellosis in BALB/c mice. Parasit Vectors 2013, 6(1):246.

25. Wang L, Wang ZQ, Cui J: Protein changes in Trichinella spiralis muscle larvae in vitro induced by bovine bile. Vet Parasitol 2013, 194(2-4):164-167.

26. Bradford MM: A rapid and sensitive method for the quantitation of microgram quantities of protein utilizing the principle of protein-dye binding. Anal Biochem 1976, 72:248-254.

27. Ni XD, Wang N, Liu YJ, Lu CP: Immunoproteomics of extracellular proteins of the Aeromonas hydrophila China vaccine strain J-1 reveal a highly immunoreactive outer membrane protein. FEMS Immunol Med Microbiol 2010, 58(3):363-373.

28. Cui J, Liu RD, Wang L, Zhang X, Jiang P, Liu MY, Wang ZQ: Proteomic analysis of surface proteins of Trichinella spiralis muscle larvae by two-dimensional gel electrophoresis and mass spectrometry. Parasit Vectors 2013, 6(1):355.

29. Wang SW, Wang ZQ, Cui J: Protein change of intestinal epithelial cells induced in vitro by Trichinella spiralis infective larvae. Parasitol Res 2011, 108(3):593-599.

30. Li G, Waltham M, Anderson NL, Unsworth E, Treston A, Weinstein JN: Rapid mass spectrometric identification of proteins from two-dimensional polyacrylamide gels after in gel proteolytic digestion. Electrophoresis 1997, 18(3-4):391-402.

31. Robinson MW, Greig R, Beattie KA, Lamont DJ, Connolly B: Comparative analysis of the excretory-secretory proteome of the muscle larva of Trichinella pseudospiralis and Trichinella spiralis. Int J Parasitol 2007, 37(2):139-148.

32. Zdobnov EM, Apweiler R: InterProScan-an integration platform for the signature-recognition methods in InterPro. Bioinformatics 2001, 17(9):847-848,

33. Ye J, Fang L, Zheng H, Zhang Y, Chen J, Zhang Z, Wang J, Li S, Li R, Bolund L: WEGO: a web tool for plotting GO annotations. Nucleic Acids Res 2006, 34(Web Server issue):W293-W297.

34. Dzik JM: Molecules released by helminth parasites involved in host colonization. Acta Biochim Pol 2006, 53(1):33-64

35. Hewitson JP, Grainger JR, Maizels RM: Helminth immunoregulation: the role of parasite secreted proteins in modulating host immunity. Mol Biochem Parasitol 2009, 167(1):1-11.

36. van Die I, Cummings RD: Glycan gimmickry by parasitic helminths: a strategy for modulating the host immune response? Glycobiology 2010, 20(1):2-12.

37. Bolas-Fernandez F, Corral Bezara LD: TSL-1 antigens of Trichinella: an overview of their potential role in parasite invasion, survival and serodiagnosis of trichinellosis. Res Vet Sci 2006, 81(3):297-303.

38. Gomez-Morales MA, Ludovisi A, Amati M, Blaga R, Zivojinovic M, Ribicich M, Pozio E: A distinctive Western blot pattern to recognize Trichinella infections in humans and pigs. Int J Parasitol 2012, 42(11):1017-1023.

39. Criado-Fornelio A, de Armas-Serra C, Gimenez-Pardo C, Casado-Escribano N, Jimenez-Gonzalez A, Rodriguez-Caabeiro F: Proteolytic enzymes from Trichinella spiralis larvae. Vet Parasitol 1992, 45(1-2):133-140. 
40. Moczon T, Wranicz M: Trichinella spiralis: proteinases in the larvae. Parasitol Res 1999, 85(1):47-58.

41. Todorova VK: Proteolytic enzymes secreted by larval stage of the parasitic nematode Trichinella spiralis. Folia Parasitol (Praha) 2000, 47(2):141-145.

42. Nagano I, Wu Z, Nakada T, Boonmars T, Takahashi Y: Molecular cloning and characterization of a serine proteinase gene of Trichinella spiralis. J Parasitol 2003, 89(1):92-98.

43. Romaris F, North SJ, Gagliardo LF, Butcher BA, Ghosh K, Beiting DP, Panico M, Arasu P, Dell A, Morris HR, et al: A putative serine protease among the excretory-secretory glycoproteins of L1 Trichinella spiralis. Mol Biochem Parasitol 2002, 122(2):149-160.

44. Bien J, Nareaho A, Varmanen P, Gozdzik K, Moskwa B, Cabaj W, Nyman TA, Savijoki K: Comparative analysis of excretory-secretory antigens of Trichinella spiralis and Trichinella britovi muscle larvae by two-dimensional difference gel electrophoresis and immunoblotting. Proteome Sci 2012, 10(1):10.

45. MacLea KS, Krieser RJ, Eastman A: A family history of deoxyribonuclease II: surprises from Trichinella spiralis and Burkholderia pseudomallei. Gene 2003, 305(1):1-12.

46. Liu MF, Wu XP, Wang XL, Yu YL, Wang WF, Chen QJ, Boireau P, Liu MY: The functions of Deoxyribonuclease II in immunity and development. DNA Cell Biol 2008, 27(5):223-228.

47. Gounaris K: Nucleotidase cascades are catalyzed by secreted proteins of the parasitic nematode Trichinella spiralis. Infect Immun 2002, 70(9):4917-4924.

48. Heussler VT, Dobbelaere DA: Cloning of a protease gene family of Fasciola hepatica by the polymerase chain reaction. Mol Biochem Parasitol 1994, 64(1):11-23.

49. Cox GN, Pratt D, Hageman R, Boisvenue RJ: Molecular cloning and primary sequence of a cysteine protease expressed by Haemonchus contortus adult worms. Mol Biochem Parasitol 1990, 41(1):25-34.

50. Ramesh MV, Sirakova T, Kolattukudy PE: Isolation, characterization, and cloning of CDNA and the gene for an elastinolytic serine proteinase from Aspergillus flavus. Infect Immun 1994, 62(1):79-85.

51. Trap C, Fu B, Le Guerhier F, Liu M, Le Rhun D, Romand T, Perret C, Blaga R, Boireau P: Cloning and analysis of a CDNA encoding a putative serine protease comprising two trypsin-like domains of Trichinella spiralis. Parasitol Res 2006, 98(4):288-294.

doi:10.1186/1756-3305-7-40

Cite this article as: Wang et al:: Identification of early diagnostic antigens from major excretory-secretory proteins of Trichinella spiralis muscle larvae using immunoproteomics. Parasites \& Vectors 2014 7:40.

\section{Submit your next manuscript to BioMed Central and take full advantage of:}

- Convenient online submission

- Thorough peer review

- No space constraints or color figure charges

- Immediate publication on acceptance

- Inclusion in PubMed, CAS, Scopus and Google Scholar

- Research which is freely available for redistribution 